\title{
A Survey on Enhanced Energy Efficient Routing Protocol of WSN for
}

\author{
Internet of Things \\ Bhukya Suresh $^{1}$, G Shyama Chandra Prasad ${ }^{2}$ \\ ${ }^{1}$ Research Scholar, Department of Computer Science \& Engineering, Osmania University, Hyderabad, Telangana, India. \\ ${ }^{2}$ Associate Professor, Department of Information Technology, Matrusri Engineering College, Hyderabad, Telangana, India. \\ Email: 'b.suresh48@gmail.com, ${ }^{2}$ gscprasad@gmail.com
}

\begin{abstract}
Wireless Sensor Networks (WSNs) are a resource-constrained network class recognized as a major energy consumer. Wireless sensor technologies are used in many commercialized industrial automation processes and other real-world applications. The WSN protocol is well-suited to harsh situations where deployment is difficult or impossible, such as the battlefield, a toxic chemical plant, the cloud, fog computing, and the Internet of Things, but not in a high-temperature network infrastructure environment. WSNs have introduced various Energy-Efficient Routing Protocols based on network (NW) organization and protocols in recent years. Various WSN routing options for energy efficiency are explored in this work. The WSN Energy Efficient Routing Protocol is compared to other routing systems. We also compare and investigate better WSN routing algorithms for cloud computing, fog computing, and the Internet of Things.
\end{abstract}

Keywords- Cloud Computing, Energy Efficiency Routing Protocols, Energy Efficiency,Fog Computing, Internet of Things, Wireless Sensor Network.

\section{INTRODUCTION}

The Wireless Sensor Network (WSN) is widely used for environmental monitoring, traffic control, health care, as well as commercial and family needs. This NW form consists of self-organizing sensor nodes (SNs) that are fixed. SNs can add, process, and transfer raw data to the BS node, then sent to the Internet. The wireless transceiver, data storage, CPU, and power are all connected by a wireless SN. SN uses a practical energy routing approach to extend the life of WSN in a hostile environment or a place with low node energy [1]. WSN systems have sparked much interest in sectors like engineering and science, even though they're still a young field of research. As the Internet of Things (IoT) has progressed, the scope of a wireless mesh network (WMN) and wireless sensor network (WSN) research and development has expanded significantly. In an NW, data routing is a critical operation that consumes much energy. The amount of energy spent on determining if routing in NW is efficient, such as direction, node power, connection performance, traffic, and so on, can add up quickly. The Internet of Things [2], a popular technology today, allows for greater study and development of these components, such as networks, detectors, new protocols, and optimization methods. In IoT systems, networking is crucial, and boosting these NWs is critical to improving the systems' performance. The network gets more stable as its lifespan rises. This can be accomplished by improving the NW usage protocol, which allows network nodes to conserve energy. Sensor NWs are used in various data gathering applications to improve network performance, longevity, and capacity efficiency. The initial node's network lifespan is the amount of time it takes to run on battery power. The network's ability and lifetime are two significant goals [3]. Two of WSN's key concerns are energy efficiency and delivery time. LEACH (Reduced Energy Adaptive Clustering Hierarchy) routes have a low delivery interruption when compared to other hierarchical routing. In WSN implementation, LEACH is the most extensively utilized routing algorithm.

Extreme circumstances, such as increased mobility, congested traffic, and other factors affecting service quality, are now a reality. To help, new technology is necessary [4]. The LEACH protocol employs different access TDMA (Time Division Multiple Access) mechanisms to determine when data should be supplied. Data transmission costs more energy when the distance between the BS and the $\mathrm{CHs}$ is higher than the threshold distance. LEACH has been optimized to reduce energy consumption by installing MS and rendezvous nodes in the $\mathrm{RN}$ area [5].

Because of the steady operational states provided by IoT, a vast volume of data is growing exponentially. Such IoT devices generate a flood of data, disrupting expected data processing and analytics capabilities previously controlled faultlessly through the cloud. Fog computing design solves these disruptions by focusing on deploying micro clouds (fog nodes) on the edge of data sources with efficient cloud system complement characteristics. Extensive IoT data analytics using a fog computing framework is in the early stages of development and will necessitate substantial study to create more data and make more informed judgments [6].

Because of the continuous operational states given by IoT, a massive amount of data is being generated at an exponential rate. Such IoT devices generate a torrent of data, disturbing the cloud's expected data processing and analytics capabilities, which were previously flawlessly regulated. By focusing on deploying micro clouds (fog nodes) on the edge of data sources with effective cloud system complement properties, fog computing design 
eliminates these disturbances. Large-scale IoT data analytics employing a fog computing framework is still in its infancy, and additional research is needed to generate more data and make more educated decisions [6].

The remainder of the paper is laid out as follows: The second section gives an overview of RP and a taxonomy analysis. Section 3 discusses EERP, how to improve it in a WSN, and how to use IoT, Cloud Computing (CC), and Fog Computing(FC) in a WSN. In WSN, Section 4 gives a comparison based on their EERP and EEERP parameters. Section 4 delves into the context and ramifications of various routing protocols in emerging industries, including the Internet of Things, Fibre Channel, and Cloud Computing.

By providing for fast communication, dependable inspection, and job execution, WSNs have become a critical component of a wide range of applications, including environmental monitoring, military surveillance, and medical. WSNs are made up of a densely distributed network of sensor nodes that communicate wirelessly to deliver and receive environmental data. One or more sensors, a radio transmitter, a processor, and a power supply are all included in each sensor node. WSN development becomes a complex procedure due to the complexity of such systems. Several additional essential conditions must be met during creating a WSN, including the fundamental requirement of power consumption. As a result, several recent research has focused on WSNs. The authors explained what WSNs are and how they work.

The authors evaluated different sensor localization techniques and hierarchical taxonomy and their applicability in various contexts in their paper. They demonstrated new sensor localization algorithms and how they might be implemented in IoT infrastructure. The authors also presented a survey on sensor-free localization for the intelligent world in the same context. The authors looked at nine different WSN modeling methodologies. They demonstrated how each methodology describes the behavior of nodes and networks. They also demonstrated each approach's modeling tool. We present a study that gathers and examines existing data in this work, motivated by this idea.

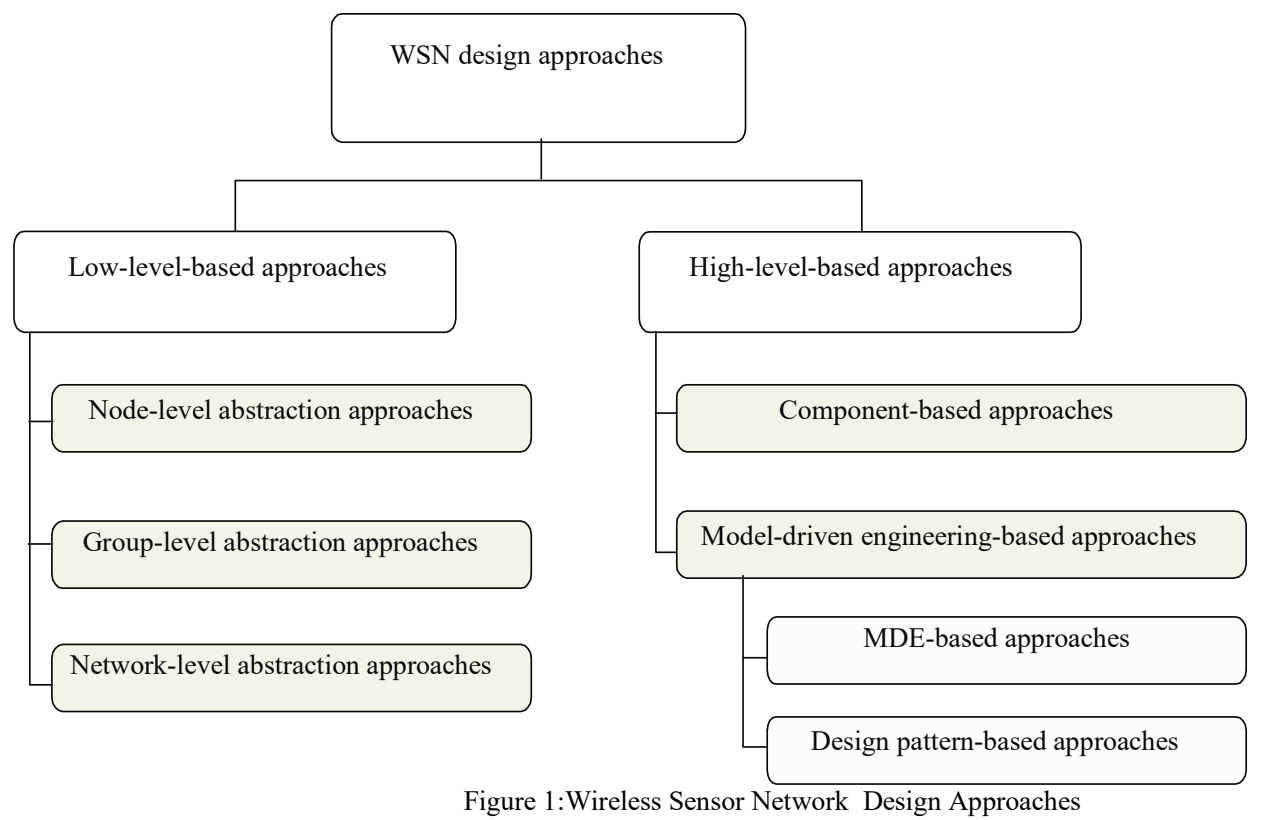

\section{Taxonomy}

The transmission of data is the most energy-intensive body in WSNs. It necessitates the shortest possible transfer to a Base Station (BS), with all decision-making taking place at the node level. When the number of nodes and network size expands, scalability becomes even more crucial. The entire NW is divided into many virtual layers (clusters), and nodes in the same layer will have the same job. As the cluster's $\mathrm{CH}$, some of the nodes are utilized to manage jobs between the nodes. Clustering decreases or aggregates network load by exploiting data correlation, resulting in increased energy efficiency. CHS collects and aggregates information from nodes before sending it to BS [10]. 


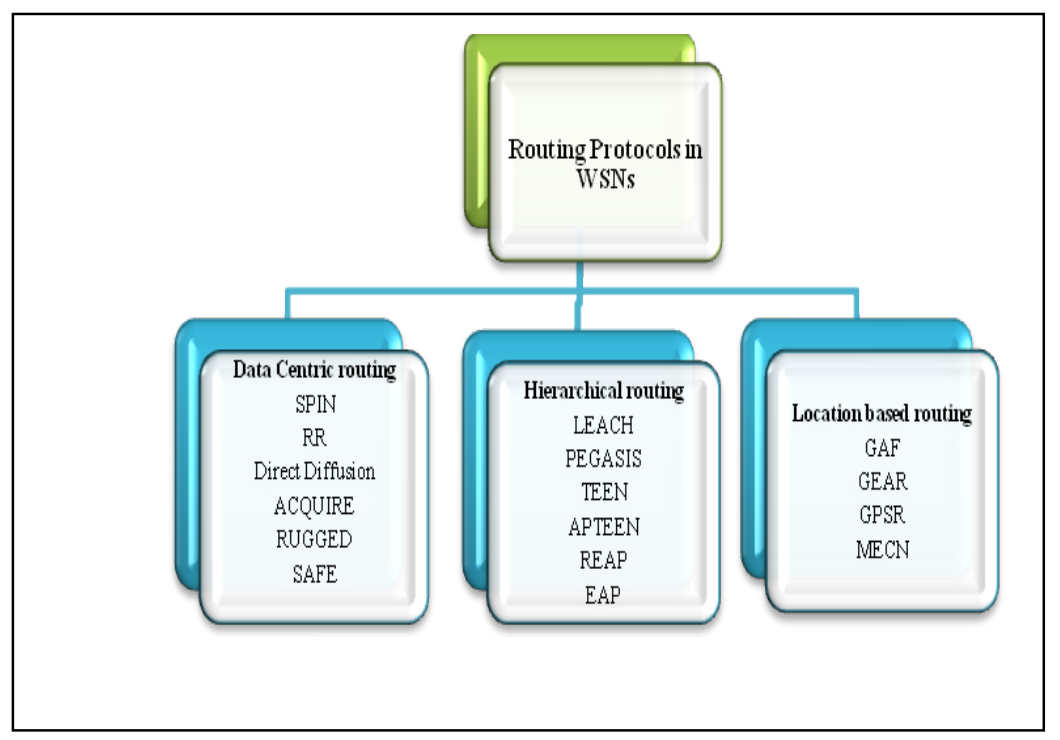

Figure 2.Routing Protocols.

Location-based Routing Protocols (LRPs), Hierarchical-based Routing Protocols (HRPs), and Flat-based Routing Protocols (FRPs) or Data Centric Routing Protocols are the three types of WSN Routing Protocols shown in Figure 2. (DRPs). Flat routing protocols assign all WS nodes equal functions and roles. Many nodes are assigned diverse roles and functions in hierarchical routing; however, in local routing, wireless sensor nodes are employed for data transfer[9].

\section{Routing in the Internet of Things}

Because nodes on the IoT network operate as hosts or routers, a path is required. For sensor networks and IoT applications, several routing algorithms have been proposed. Data flow from source to destination has an impact on transmission node electricity usage. The Internet of Things (IoT) has been a hot topic in wireless communication in recent years. Portable short-range transceivers are rapidly being developed for integration into a wide range of other devices and items, allowing for new sorts of interaction with things and people, as well as between them. IoT nodes are made up of sensor modules, processing modules, wireless connection modules, and control modules. There is no central control node in the network, and all nodes are in the same position. Grid nodes must react to complex position changes and find network routing in the lowest amount of time. A uniform IoT routing protocol standard has yet to emerge. Finding an appropriate IoT routing protocol is crucial. The overall routing, average end-to-end speed, and performance of various protocols were compared by changing the total number or percentage of nodes.

\section{Routing Protocol in IoT Applications}

WSNs are crucial to the Internet of Things' growth and expansion because they allow low-cost devices with limited capabilities to connect to the Internet and provide life-changing applications. One of the key standards that enable low-energy and lossy networks is IEEE standard 802.15.4, which serves as the backbone of WSNs such as the IoT component (LLNs). This standard specifies the physical and data-link layers of a network, as well as a low-cost operating framework. In recent years, the Internet of Things (IoT) has emerged as an exciting and promising paradigm for connecting more physical "things" to the Internet for various purposes. Though it has become a key enabler for various next-generation applications, it has also presented new issues for overburdened networks. The Internet of Things is already being developed in healthcare and smart settings, with many low-power sensors and actuators being added to improve our lives and deliver new public services. RPL is an LLN RP designed by the Internet Engineering Task Force (IETF) and standardized in RFC6550 in 2012. RPL received much interest, and several research papers were produced to analyze and enhance performance in various applications. 
Table I: The IoT Security Requirements at a Higher Level

\begin{tabular}{|c|c|}
\hline Internet of Things Layer & The Requirements of Security \\
\hline The Application & $\begin{array}{ll}\text { - } & \text { The Applications for Data Minimization } \\
\text { - } & \text { Policy Management \& Privacy Protection } \\
\text { - } & \text { Authorization, Assurance, Authentication } \\
\text { applications }\end{array}$ \\
\hline The Services support & 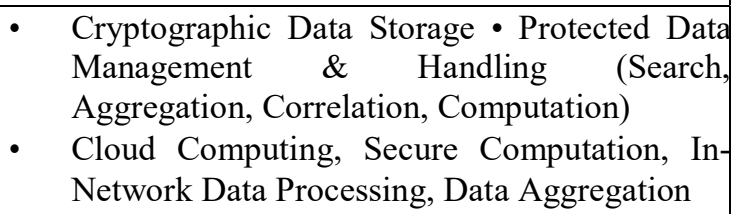 \\
\hline The Network layer & $\begin{array}{ll} & \text { Cross-domain Data Security Handling; } \\
\text { - } & \text { Cloud Interaction/ Secure Sensor } \\
\text { - } & \text { Security of Connectivity and Communication }\end{array}$ \\
\hline The Sensor/ Smart object & $\begin{array}{l}\text { Data Format \& Structures } \\
\text { Access Control to Nodes } \\
\text { Lightweight Encryption } \\
\text { - Attestation \& Trust Anchors }\end{array}$ \\
\hline
\end{tabular}

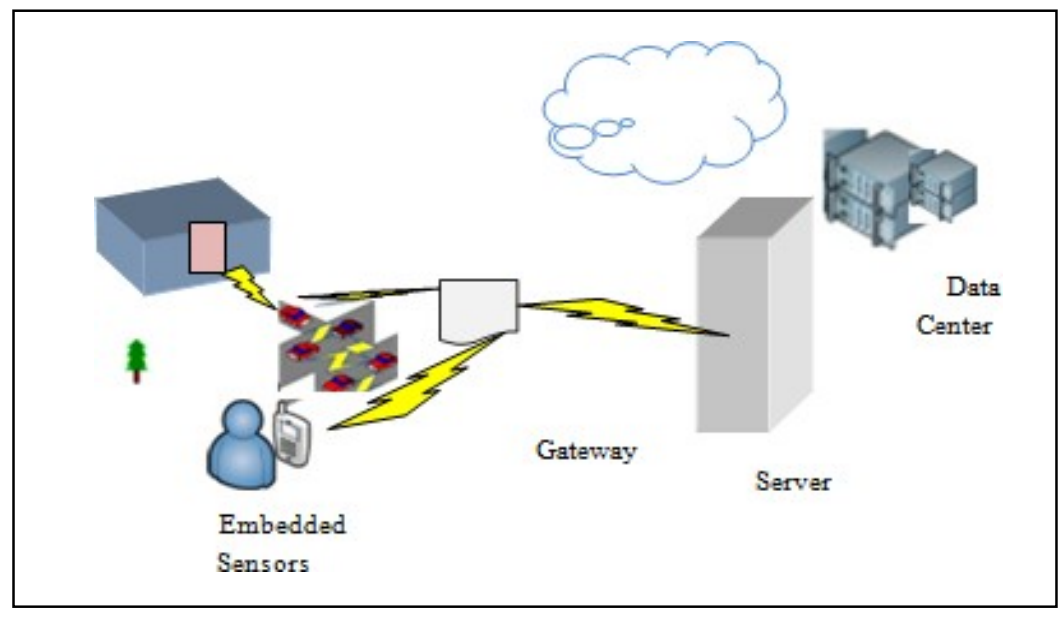

Figure 3.The Internet of Things in the Routing

Figure 3 shows how IoTs can be used in a variety of ways. IoTs are divided into three levels [ 30]. Many sensors are installed into Tier I to monitor objects and their surroundings. Level II is a node that collects data from built-in apps and serves it as a gateway. Traditional smartphone portals are superior apps to integrated sensors. Tier III includes servers or data centers that store and analyze data received from gateway nodes. Gateway nodes are used by servers or data centers to undertake complicated analysis by creating models.

Every day, the expanding popularity of WSNs puts this technology to use in today's modern environment. Because all things in the Internet of Things are connected, WSNs can be employed effectively. The capabilities of today's WSNs may allow for the completion of challenging tasks such as data fusion. SNs can be outfitted with a variety of components to suit a variety of applications. The main problem of WSNs is that they have limited power consumption, computation capabilities, and memory capacity. A fundamental difficulty in WSN protocols is increasing the life of sensor networks. There are numerous techniques to reduce energy consumption and extend the life of NW in WSNs. Many protocols like this will help WSNs live longer and better lives. These protocols transmit data to the sink node and convey data from the sink node to the cloud. These protocols are used to send data to the cloud and to relay information to the sink node. The concept of FC, on the other hand, is used in WSN routing protocols. Every round, cluster head $(\mathrm{CH})$ picks are organized under 
this protocol. By selecting nodes based on low energy cluster head $(\mathrm{CH})$, helps to avoid the usage of heterogeneous energy. Optimizing the minimal distance between cluster head $(\mathrm{CH})$ and FNs, choosing specific $\mathrm{CHs}$ for FN data, and lowering the total overhead of each FN could all assist extend the life of a network.

Older mobile phones have grown into contemporary, sophisticated Smartphones that can run a variety of apps and do a variety of functions. Mobile battery life is a big issue for smartphones, and it can be remedied by unloading and storing mobile cloud data to extend battery life. In a cloud context, securing important data against adversaries is difficult. The importance of communication protocols in the cloud environment cannot be overstated. Secure data transmission necessitates the use of a defined communication protocol.

The principles of cloud computing and the many routing techniques that have been employed to improve cloud network performance. The JSQ method provides the best outcomes in those methods, and a shorter path scheduling method provides a region route to reach. Multicast routing is used by optical NWs, while optimization methods are used by WSNs.

\section{LITERATURE SURVEY}

This section will go over the details of EERP (Energy Efficient Routing Protocol) in WSNs, and EEERP (Enhance Energy Efficient Routing Protocol) is another growing industry.

Zhibo Pang et al. produced hardware named inbox. To establish medical facilities. The Internet-of-Things (IoT)-based in-home healthcare services have a lot of potential in the business world. The issues associated with the integration of WSN and RFID technologies have been presented by Li Wang et al. One of the most difficult issues is the low communication efficiency caused by duplicate data. The proposed method employs a data cleaning algorithm to reduce duplicated data effectively.

Mihai T. Lazarescu showed the practical design and construction of a fully working WSN platform for various long-term environmental monitoring IoT applications.

Shancang $\mathrm{Li}$ et al. have devised a method for data sampling and acquisition in wireless sensor networks and the Internet of Things that uses compression sensing theory. In the Internet of Things, there is a smart grid.

Siyuan Chen proposed that there should be a limit or bound for obtaining data. To address this problem, the suggested method uses a wireless sensor network to collect data.

Liu and P. Zhang [2018] present a new load balancing (LB) technique for WSN data transmission called super-connection-based data drainage, which redistributes data traffic by leveraging supernodes' more robust hardware and better communication capacity. Because it differs from traditional passive late treatments, it is both a positive and an early intrusive method. The fundamental idea is to send data to people with low data traffic from extremely far locations on the Internet via a data traffic jump [13]. An estimation function is used to identify the best start and ending locations for super connections.

S. N. Mishra et al. [2018], the performance of a huge network's protocols is destroyed. To overcome this issue, the Scalable Survival Path Routing (SSPR) protocol has been proposed. The protocol uses a weight-based clustering strategy that considers the energy and node degree available in two parameters to determine node weight and then chooses the node with the highest weight as its cluster head $(\mathrm{CH})$ simulation results to show that Scalable Survival Path Routing(SSPR) outperforms previous large network algorithms [17].

K. Manzoor et al. [2018] focused on the WSN protocol and ensuring stable node connectivity. A unique $\mathrm{CH}$ selection methodology has been introduced to increase the energy efficiency of TL- LEACH and Extended LEACH (ETL-LEACH). According to simulation results, ETL-LEACH considerably improves energy efficiency, node life, and communication delay (SRs).

Z. Sun et al.[2019] Propose an energy-efficient Cross-layer Clustering Model (ECCM) for Mobile Intelligent FC. The proposed algorithm then uses a sensing-event-driven methodology based on cross-layer projection theory to project fog nodes onto the sensing layer, resulting in a strong virtual control node. After that, fog computation is employed to produce distributed clustering of event-field nodes using the fog layer's clusterbased RP control method. The second is effective data aggregation routing, which concentrates the fog nodes on a projectile. By replacing information in the sensor's bottom layer routing and balancing, it reduces the NW burden. Third, we use the Particles Swarm Optimization (PSO) methodology to optimize RP by selecting suitable node groups as cluster head $(\mathrm{CH})$. NW's above energy may be effectively minimised and balanced, minimizing node weariness and extending network lifetime, with the exception of specific overhead competition. Finally, simulation results show that the routing structure is simple to construct and maintain, boosting the efficiency of the NW technique for data aggregation.

\section{The Comparative Study}

We present EERP in WSN based on its classifications and different parameters, as well as a comparison with EEERP based on protocols, applications, and their advantages and disadvantages Table II 
Table II. The Energy Efficient Routing Protocols (EERP) Comparison

\begin{tabular}{|c|c|c|c|c|c|c|c|}
\hline $\begin{array}{l}\text { Routing } \\
\text { protocols }\end{array}$ & Classification & Mobility & $\begin{array}{l}\text { Power } \\
\text { Usage }\end{array}$ & $\begin{array}{l}\text { Aggrega } \\
\text { tion of } \\
\text { data }\end{array}$ & $\begin{array}{c}\text { Localizatio } \\
\mathbf{n}\end{array}$ & $\begin{array}{c}\text { Scalabilit } \\
\mathbf{y}\end{array}$ & $\begin{array}{l}\text { Query- } \\
\text { based }\end{array}$ \\
\hline SPIN & $\begin{array}{l}\text { Flat or Negotiation } \\
\text { based }\end{array}$ & Yes & Limited & Yes & Yes & Limited & Yes \\
\hline $\mathrm{DD}$ & $\begin{array}{l}\text { Flat or Diffusion } \\
\text { based }\end{array}$ & Limited & Limited & Yes & Yes & Limited & Yes \\
\hline RR & $\begin{array}{l}\text { Flat or Diffusion } \\
\text { based }\end{array}$ & No & $\mathrm{N} / \mathrm{A}$ & Yes & No & Good & Yes \\
\hline $\begin{array}{l}\text { COUG } \\
\text { AR }\end{array}$ & Flat or Data-Centric & No & Limited & Yes & No & Limited & Yes \\
\hline $\begin{array}{l}\text { ACQUI } \\
\text { RE }\end{array}$ & $\begin{array}{l}\text { Flat or Data- } \\
\text { Centric }\end{array}$ & Limited & N/A & Yes & No & Limited & Yes \\
\hline LEACH & $\begin{array}{l}\text { Hierarchical or } \\
\text { Block based }\end{array}$ & Fixed BS & $\begin{array}{l}\text { Maximum } \\
\mathrm{m}\end{array}$ & Yes & Yes & Good & No \\
\hline TEEN & $\begin{array}{l}\text { Hierarchical or } \\
\text { Block based }\end{array}$ & Fixed BS & $\begin{array}{l}\text { Maximum } \\
\mathrm{m}\end{array}$ & Yes & Yes & Good & No \\
\hline PANEL & $\begin{array}{l}\text { Hierarchical or } \\
\text { Grid-based }\end{array}$ & Yes & Limited & No & Yes & Low & No \\
\hline
\end{tabular}




\begin{tabular}{|c|c|c|c|c|c|c|c|}
\hline TTDD & $\begin{array}{c}\text { Hierarchical } \\
\text { or grid- } \\
\text { based }\end{array}$ & Yes & Limited & No & No & Low & No \\
\hline PEGASIS & $\begin{array}{l}\text { Hierarchical } \\
\text { or Chain } \\
\text { based }\end{array}$ & $\begin{array}{l}\text { Fixed } \\
\text { BS }\end{array}$ & Maximum & No & Yes & Good & No \\
\hline CCS & $\begin{array}{l}\text { Hierarchical } \\
\text { or Chain } \\
\text { based }\end{array}$ & $\begin{array}{l}\text { Fixed } \\
\text { BS }\end{array}$ & Maximum & No & Yes & Good & No \\
\hline GAF & $\begin{array}{c}\text { Location- } \\
\text { based or area } \\
\text { partition }\end{array}$ & Limited & Limited & No & No & Good & No \\
\hline GRID & $\begin{array}{l}\text { Location- } \\
\text { based } \\
\text { repartition }\end{array}$ & No & Limited & No & Yes & Good & Yes \\
\hline GPSR & $\begin{array}{l}\text { Location- } \\
\text { based or } \\
\text { OptimalPath }\end{array}$ & Limited & Limited & No & No & Limited & No \\
\hline GEAR & $\begin{array}{l}\text { Location- } \\
\text { based or } \\
\text { Optimal Path }\end{array}$ & Limited & Limited & No & No & Limited & No \\
\hline
\end{tabular}

Table III.Comparison Of Enhanced Energy Efficient Routing Protocol (EEERP) In WSN

\begin{tabular}{|c|c|c|c|}
\hline Protocol & Pros & Cons & Applications \\
\hline ELBSEP & $\begin{array}{l}\text { It cuts down on } \\
\text { transmission time. }\end{array}$ & $\begin{array}{l}\text { The SNs will never } \\
\text { communicate if the } \\
\text { threshold values are } \\
\text { not satisfied. }\end{array}$ & It is the best ideal for time-critical tasks. \\
\hline Z-SEP & Low usage of energy. & $\begin{array}{l}\text { Other complexity and } \\
\text { long interruption. }\end{array}$ & $\begin{array}{l}\text { This is suitable for both time-critical and } \\
\text { non-critical applications. }\end{array}$ \\
\hline SEP & $\begin{array}{l}\text { It improves network } \\
\text { longevity, stability, } \\
\text { and performance. }\end{array}$ & $\begin{array}{l}\text { It doesn't support } \\
\text { nodes' multi-level } \\
\text { heterogeneity. }\end{array}$ & $\begin{array}{l}\text { This might be used for everything from } \\
\text { machinery supervision to defect } \\
\text { identification and diagnosis. }\end{array}$ \\
\hline TAG & $\begin{array}{l}\text { It reduces the quantity } \\
\text { of data transmitted via } \\
\text { sensor NW. }\end{array}$ & Overhead enhances. & $\begin{array}{l}\text { This may be utilized for supervising } \\
\text { machine }\end{array}$ \\
\hline REEM & $\begin{array}{l}\text { Fault-tolerant and } \\
\text { reliable. }\end{array}$ & $\begin{array}{l}\text { Due to many paths, } \\
\text { overhead expenses and } \\
\text { energy consumption } \\
\text { may rise. }\end{array}$ & $\begin{array}{l}\text { It can be used in situations where } \\
\text { dependability and security are critical. }\end{array}$ \\
\hline
\end{tabular}




\begin{tabular}{|c|c|c|c|}
\hline SAR & $\begin{array}{l}\text { It maintains a number } \\
\text { of routes to the goal. }\end{array}$ & $\begin{array}{l}\text { The high cost of maintaining } \\
\text { tables and the state for each } \\
\text { SN. }\end{array}$ & $\begin{array}{l}\text { It could be used in situations when } \\
\text { QoS is a major issue. }\end{array}$ \\
\hline SWE & $\begin{array}{l}\text { It builds a hop } \\
\text { spanning tree with the } \\
\text { bare minimum of hops } \\
\text { (MHST) }\end{array}$ & This is a composite protocol. & $\begin{array}{l}\text { This might be used to keep an eye } \\
\text { on a machine. }\end{array}$ \\
\hline MWE & $\begin{array}{l}\text { Reduce the } \\
\text { energy path of every } \\
\text { source } \\
\text { a node within } \\
\text { every network SN is } \\
\text { set. }\end{array}$ & $\begin{array}{l}\text { Greater overhead Less } \\
\text { scalability more time. }\end{array}$ & $\begin{array}{l}\text { It may be utilized to supervise } \\
\text { machines. }\end{array}$ \\
\hline SIO & $\begin{array}{l}\text { It extends the } \\
\text { lifetime of the } \\
\text { NW }\end{array}$ & More Delay & $\begin{array}{l}\text { It's possible to use it in the medical } \\
\text { industry. }\end{array}$ \\
\hline MIP & Useless energy. & More Delay & $\begin{array}{l}\text { It was incorporated into large-scale } \\
\text { NWs. }\end{array}$ \\
\hline EESRA & $\begin{array}{l}\text { Despite the increased } \\
\text { NW size, EESRA will } \\
\text { extend the network's } \\
\text { life. EESRA reduces the } \\
\text { load on CHs and selects } \\
\text { CHs at random. }\end{array}$ & $\begin{array}{l}\text { EESRA performance is } \\
\text { reflected by average waste } \\
\text { energy per round as well as } \\
\text { energy consumption rate for } \\
\text { all active SNs. }\end{array}$ & $\begin{array}{l}\text { To develop a hybrid WSN MAC } \\
\text { protocol, EESRA uses multi-hop } \\
\text { transmissions and intra-cluster } \\
\text { communication. }\end{array}$ \\
\hline
\end{tabular}

\section{FUTURE CHALLENGES AND SCOPE}

Future studies will concentrate on different routing options. Energy variance in LEACH, HUMS, and AERP is minimal compared to the RPs mentioned above, and CBCA is minor. While CBCA is comparable to other RPs, it is necessary to re-adjust the energy variance. Extending network life was also of major importance due to resource constraints in WSNs. Necessary research should be conducted to improve the life of wireless sensors Network.

The wireless sensor network is in charge of sensing and relaying data to the base station, which results in physical events. In a network of power limit sensors, routing is a key tool for tracking and data transfers. Initially, nodes can send and receive data through node-defined routes. If sensed data is accessible in some network segments.

\section{CONCLUSION}

A WSN comprises self-contained, geographically distributed sensors that can reliably monitor various military and civilian surroundings and send data to a central location via a network. RPs heavily influence the energy consumption of sensor networks. For this kind of network, and energy-efficient routing method is necessary. Thanks to the Internet of Things, we now have a growing number of energy-efficient protocols and algorithms to improve the system as a whole. Whether it's data routing in NW, optimizing the energy efficiency of NW nodes, extending the life of NW, or making NW smarter so that it can make its judgments based on previously obtained data, there's something for everyone, the possibilities are endless. Most SNs are used for data transfer to the base station because of their energy. As a result, they utilize their energy at a considerably faster rate. Extending network life was of significant importance in WSNs due to resource constraints. A proportionate study of EERPs was conducted. 


\section{REFERENCES}

[1] F. Junli, W. Yawen and S. Haibin, "An improved energy- efficient routing algorithm in software define wireless sensor network," IEEE International Conference on Signal Processing, Communications and Computing(ICSPCC), Xiamen, 2017, pp. 1-5. doi: 10.1109/ICSPCC.2017.8242610.

[2] A. S. Hampiholi and B. P. Vijaya Kumar, "Efficient routing protocol in IoT using modified Genetic algorithm and its comparison with existing protocols," 3rd International Conference on Circuits, Control, Communication and Computing (I4C), Bangalore, India, 2018, pp. 1-5. DOI: 10.1109/CIMCA.2018.8739759.

[3] R R. Tejas and T. H. M. Devi, "Design and implementation of an efficient routing schemes to increase distribute lifetime efficiency in WSN," IEEE International Conference on Recent Trends in Electronics, Information \& Communication Technology (RTEICT), Bangalore, 2016, pp. 637-640. DOI: 10.1109/RTEICT.2016.7807900

[4] M. A. Rahmadhani, L. V. Yovita, and R. Mayasari, "Energy Consumption and Packet Loss Analysis of LEACH Routing Protocol on WSN Over DTN," 4th International Conference on Wireless and Telematics (ICWT), Nusa Dua, 2018 , pp. 1- 5. DOI:10.1109/ICWT.2018.8527827.

[5] S. Kumar, A. Verma, P. R. Gautam, A. Dayal, and A. Kumar, "The Load Balancing of Optimizing LEACH Clustering Algorithm with Mobile Sink and Rendezvous Nodes," 5th IEEE Uttar Pradesh Section International Conference on Electrical, Electronics and Computer Engineering (UPCON), Gorakhpur, 2018, pp.1-6.DOI: 0.1109/UPCON.2018.8596989.

[6] Muhammad RizwanAnawar, Shangguang Wang, Muhammad Azam Zia, Ahmer Khan Jadoon, UmairAkram and Salman Raza "Fog Computing: An Overview of Big IoT Data Analytics", Hindawi Wireless Communications and Mobile Computing, Volume 2018, pp. 1-22. https://doi.org/10.1155/2018/7157192.

[7] W. B. Heinzelman, A. P. Chandrakasan, and H. Balakrishnan, "An application-specific protocol architecture for wireless microsensor networks," IEEE Trans. Wirel. Commun., vol. 1, no. 4, pp. 660-670,2002.

[8] L. Qing, Q. Zhu, and M. Wang, "Design of a distributed energy-efficient clustering algorithm for heterogeneous wireless sensor networks," Comput. Commun., vol. 29, no. 12, pp. 2230-2237, 2006

[9] T. M. Behera, S. K. Mohapatra, P. Mukherjee and H. K. Sahoo, "Work-In-Progress: DEEC-VD: A Hybrid Energy Utilization Cluster-Based Routing Protocol for WSN for Application in IoT," International ConferenceonInformation Technology (ICIT), Bhubaneswar, 2017, pp. 97- 100. DOI: 10.1109/ICIT.2017.42.

[10] HalaZayed, Mohamed Taha and Aya H. Allam, "Energy Efficient Routing In Wireless Sensor Networks: A Survey", International Conference on Electrical, Electronics, Computers, Communication, Mechanical and Computing (EECCMC), pp:1-5, 2018.

[11] Singh, H., \& Singh, D., "Taxonomy of routing protocols in wireless sensor networks: A survey", 2nd International Conference on Contemporary Computing and Informatics(IC3I), 2016. DOI:10.1109/ic3i.2016.7918796.

[12] X. Liu and P. Zhang, "Data Drainage: A Novel Load Balancing Strategy for Wireless Sensor Networks," in IEEE Communications Letters, vol. 22, no. 1, pp. 125-128, Jan. 2018. DOI:10.1109/LCOMM.2017.2751601

[13] R. Kumari and R. Kumar, "An energy-efficient hybrid optimized routing protocol for WSN," 2nd International Conference on Telecommunication and Networks (TEL-NET), Noida, 2017, pp. 1-6.doi:10.1109/TEL- NET.2017.8343505.

[14] A. Singh, S. Rathkanthiwar and S. Kakde, "Energy-efficient routing of WSN using particle swarm optimization and V- LEACH protocol," International Conference on Communication and Signal Processing (ICCSP), Melmaruvathur, 2016, pp. 2078-2082. DOI: 10.1109/ICCSP.2016.7754544.

[15] K. Tikhe and N. Sohni, "PF-RBF based energy-efficient target tracking routing algorithm for WSN," International Conference on Automatic Control and Dynamic Optimization Techniques (ICACDOT), Pune, 2016, pp. 532-537. DOI: 10.1109/ICACDOT.2016.7877642.

[16] M. Umale and S. D. Markande, "Energy-efficient routing algorithm on the target tracking in Wireless Sensor Network," International Conference on Information Processing (ICIP), Pune, 2015, pp. 176-181.DOI: 10.1109/INFOP.2015.7489373.

[17] S. N. Mishra, M. Elappila and S. Chinara, "Development of Survival Path Routing Protocol for Scalable Wireless Sensor Networks," International Conference on Information Technology (ICIT), Bhubaneswar, India, 2018, pp. 210-215. DOI:10.1109/ICIT.2018.00051

[18] K. Manzoor, S. H. Jokhio, T. J. S. Khanzada, and I. A. Jokhio, "Enhanced TL-LEACH routing protocol for large-scale WSN applications," Cybersecurity and Cyberforensics Conference (CCC), Melbourne, Australia, 2019, pp. 35-39. DOI: $10.1109 /$ CCC.2019.00-12.

[19] S. Sharma and N. Mittal, "An Improved LEACH-MF Protocol to Prolong Lifetime of Wireless Sensor Networks," IEEE 8th International Advance Computing Conference (IACC), Greater Noida, India, 2018, pp. 174-179. DOI: 10.1109/IADCC.2018.8692096.

[20] N. Kumar and Y. Singh, "Trust and packet load balancing based secure opportunistic routing protocol for WSN," 2017 4th International Conference on Signal Processing, Computing and Control (ISPCC), Solan, 2017, pp. 463-467. DOI:10.1109/ISPCC.2017.8269723.

[21] A. Abdulasik and K. Suriyakrishnaan, "Improvement of network lifetime with security and load balancing mobile data clustering for wireless sensor networks," Third International Conference on Sensing, Signal Processing and Security (ICSSS), Chennai, 2017, pp. 463-468. DOI: 10.1109/SSPS.2017.8071641.

[22] Z. Sun et al., "An Energy-Efficient Cross-Layer-Sensing Clustering Method Based on Intelligent Fog ComputinginWSNs," in IEEE Access, vol. 7, pp. 144165-144177, 2019. DOI: 10.1109/ACCESS.2019.2944858.

[23] N. Javaid, T. Hafeez, Z. Wadud, N. Alrajeh, M. S. Alabed, and N. Guizani, "Establishing a Cooperation-Based and Void Node Avoiding Energy-Efficient Underwater WSN for a Cloud," in IEEE Access, vol. 5, pp. 11582-11593, 2017. DOI: 10.1109/ACCESS.2017.2707531.

[24] S. S. Chaudhari, S. Maurya, and V. K. Jain, "MAEER: Mobility aware energy-efficient routing protocol for Internet of Things," Conference on Information and Communication Technology (CICT), Gwalior, 2017, pp. 16.doi:10.1109/INFOCOMTECH.2017.8340624.

[25] S. Santiago and L. Arockiam, "A novel fuzzy-based energy-efficient routing for Internet of Things," International Conference on Algorithms, Methodology, Models, and Applications in Emerging Technologies (ICAMMAET), Chennai, 2017, pp.1-4. doi: 10.1109/ICAMMAET.2017.8186645.

[26] S. Nisha and S. P. Balakannan, "An energy-efficient self-organizing multicast routing protocol for Internet of Things," IEEE International Conference on Intelligent Techniques in Control, Optimization and Signal Processing (INCOS), Srivilliputhur, 2017, pp. 1-5. DOI: 10.1109/ITCOSP.2017.8303106

[27] Priyanka Sharma and InderjeetKaur, "A Comparative Study on Energy Efficient Routing Protocols in Wireless Sensor Networks", IJCSI International Journal of Computer Science, Issues, Volume 12, Issue 4, July 2015 
[28] K., N., V., V., \& G. H, R., "A Comparative Analysis of Energy-Efficient Routing Protocols in Wireless Sensor Networks", Emerging Research in Electronics, Computer Science and Technology, pp. 399-405, 2013. DOI:10.1007/978-81-322- 1157-0_40.

[29] H. Kharrufa, H. A. A. Al-Kashoash and A. H. Kemp, "RPL- Based Routing Protocols in IoT Applications: A Review," in IEEE Sensors Journal, vol. 19, no. 15, pp. 5952-5967, 1 Aug.1, 2019. DOI:10.1109/JSEN.2019.2910881.

[30] Sriram Sankaran and Ramalingam Sridhar, "Modeling and Analysis of Routing in IoT Networks," Intl. Conference on Computing and Network Communications (CoCoNet'15), Dec. 16-19, 2015, Trivandrum, India, pp. 649-655.

[31] Borujeni, E. M., Rahbari, D., \&Nickray, M., "Fog- based energy-efficient routing protocol for wireless sensor networks," The Journal of Supercomputing, 2018. DOI:10.1007/s11227-018-2514-3.

[32] K.Kuppusamy and J.Mahalakshmi, "A Survey on Routing Algorithms for Cloud Computing," International Journal of Computer Applications, International Conference on Computing and Information Technology (IC2IT-2013),2013.

[33] H. Xin and K. Yang, "Routing Protocols Analysis for Internet of Things," 2nd International Conference on Information Science and Control Engineering, Shanghai, 2015, pp. 447-450. DOI: 10.1109/ICISCE.2015.104.

[34] Keyur K Patel and Sunil M Pate, "Internet of Things-IoT: Definition, Characteristics, Architecture, Enabling Technologies, Application \& Future Challenges" International Journal of Engineering Science and Computing, pp. 6122-6131, 2016. DOI $10.4010 / 2016.1482$

[35] Muhammad Awais,Ishtiaq Ali,Turki Ali Alghamdi,Muhammad Ramzan,Muhammad Tahir,Mariam Akbar,Nadeem Javaid "Towards Void Hole Alleviation: Enhanced GEographic and Opportunistic Routing Protocols in Harsh Underwater WSNs", IEEE Access,2020 DOI: 10.1109/ACCESS.2020.2996367

[36] Bilal R. Al-Kaseem;Zahraa K. Taha;Sarah W. Abdulmajeed;Hamed S. Al-Raweshidy” Optimized Energy-Efficient Path Planning Strategy in WSN With Multiple Mobile Sinks",IEEE Access,2021. 